\title{
Spark Plug with Integrated Chamber
}

\author{
Aleš Dittrich ${ }^{1}$, Stanislav Beroun ${ }^{2}$ \\ ${ }^{1}$ Technical university of Liberec, Institute for Nanomaterials, Advanced Technology and Innovation, 46117 Liberec, Czech Republic \\ ${ }^{2}$ Technical university of Liberec, Department of vehicles and engines, 46117 Liberec, Czech Republic
}

\begin{abstract}
Spark plug with integrated chamber increases the quality of ignition of homogenous mixture in the engine cylinder. Very small amount of burning mixture bursts (outflows) from chamber (so-called flame jet ignition) which heads into faster initial phase of burning. From view of cycle to cycle variations the procedure of consequent burning is more stable. Spark plug's case with integrated chamber is exposed by higher thermal stress than classis spark plug. This fact has to be respected during design of spark plug with integrated chamber. This article shows the how configuration of the lower part of spark plug with integrated chamber can change the type of spark and how flame-jet ignition will affect parameters of burning mixture during operating cycle.
\end{abstract}

\section{Introduction}

Indirect ignition of a fuel mixture in a spark ignition engine is also referred to in the literature as an indirect ignition and in English, for example, as a flame-jet [1], jet-ignition [2 - 4] or chamber / prechamber ignition [5 6]. In all the above mentioned cases, the main objective of such a solution is to cause the combustion of a relatively small volume of combustible mixture (in units of \% compared to the cylinder volume) and to ignite the fuel-air mixture remaining with this combustible fuel mixture (turbulently flowing outside the chamber). The difference between individual solutions is in the way of fuel supply, respectively. fuel mixture to the spark plug. In these cases, the chamber spark can be divided into:

- "active" with fuel in the chamber,

-"passive" with the fuel supply outside the chamber and the fuel-air mixture into the chamber by moving the piston from the bottom dead center to the upper dead center.

The Department of Vehicles and Engines (KVM) of the Technical University of Liberec (TUL) has long been addressing the issue of combustion of combustion in the piston combustion engines by the so-called chamber ignition (or the research of spark plug with integrated chamber - SPWIC). Blažek has also dealt with this topic in his dissertation work [7].

The KVM internal documents state that the experimental research program (on KVM TUL) to verify the effect of the protected space around the spark plug electrodes in the chamber, where the conditions for the development of the ignition outbreak and combustion of the fuel mixture in the chamber and the exhaust of the combustion gases and of the combustible air out of the spark plug chamber into the combustion chambers in the engine cylinder accelerate the combustion of the fuel mixture in the engine cylinder, it was in the first stage (which was carried out in 2002-2006) carried out on only one cylinder of gasoline and gas engines. The result confirmed that the fuel-air mixture in the engine cylinder is a significant potential with real possibilities to further improve the parameters of today's petrol engines.

An indicator of the quality and stability of the combustion process in the cylinder of the internal combustion engine is the variability of engine operating cycles. Variability (referred to differently - for example VAR, $\mathrm{CoV}, \ldots$ ) of cycles is usually expressed as the ratio of the standard deviation to the average value of the given parameter. Generally, the relationship for calculating parameter variability (xy) can be written according to (1). The evaluation and determination of combustion parameters from the measured indicator diagrams was carried out using SW Concerto.

$$
V A R_{x y}=\sigma_{x y} \cdot x_{y}^{-1}
$$

- $\mathrm{x}_{\mathrm{y}}$ parameter value determined by thermodynamic analysis and statistical processing of a larger set of indicator diagrams in the engine operating mode under investigation (in the case of a highpressure engine indication, a data set of 100 or 150 consecutive engine operating cycles is typically recorded).

- $\sigma_{\mathrm{xy}}$ the standard deviation of the given parameter from the statistical processing of the set of indicator diagrams.

For a modern gasoline engine in higher engine load modes, the variability of the mean pressure indicated is $\mathrm{VAR}_{\mathrm{pi}} \approx 1-2 \%$. With the engine load decreasing, $\mathrm{p}_{\mathrm{i}}$ variability increases, with high variability in particular 
idling mode. In addition to the inter-cycle variability of the mean indicated pressure, the variability of the maximum (so-called combustion) pressure in the cylinder is also interesting. Beroun [8-9] states that $\mathrm{VAR}_{\mathrm{pmax}}$ values for spark ignition engines are $\approx 8-9 \%$ (at $\lambda=1$ and $\mathrm{VAR}_{\mathrm{pi}} \approx 2 \%$ ) during the normal burning process, ie. without knocking.
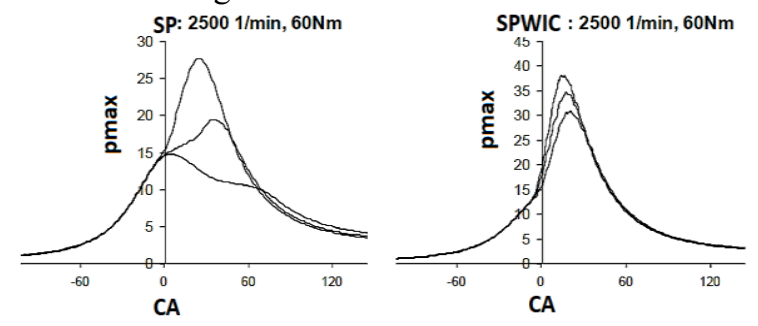

Figure 1. Comparison of gasoline engine cylinder pressure $\left(\mathrm{V}_{\mathrm{Z} 1}\right.$ $=0.35 \mathrm{dm}^{3}$, homogeneous combustion air mixture $\lambda=1$, electronic control) at standard ignition and ignition using a "folded" ignition chamber $\left(1.65 \mathrm{~cm}^{3}\right.$ chamber volume, fuel injection cylindrical compartments). Pressures from working cycles with the highest, mean and lowest $p_{\max }$ values from a set of 150 consecutive engine operating cycles. Source: internal KVM documents.

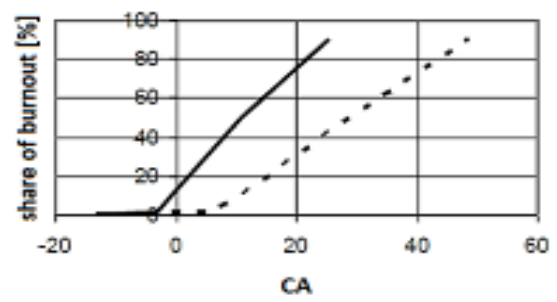

Figure 2. Running of the fuel-air mixture in the engine cylinder at spark ignition with a classic spark plug (dashed line) and chamber ignition (solid line). The parameters of the burning parameters are determined from the thermodynamic analysis of the measured pressure and statistical processing of the burning parameters from the same measurement set as the pressure steps in Figure 1. Source: KVM internal documents.

\section{Optimization work on spark plugs construction}

There were made several construction changes on spark plugs case M14 in cooperation with Brisk company (version 1 - version 6 shown in Table 1). Inner diameter of case was increased to make maximal potencial volume of integrated chamber. Lowest part of case was designed for laser welding of circle shaped case ground from fireproof material (ground a electrode).
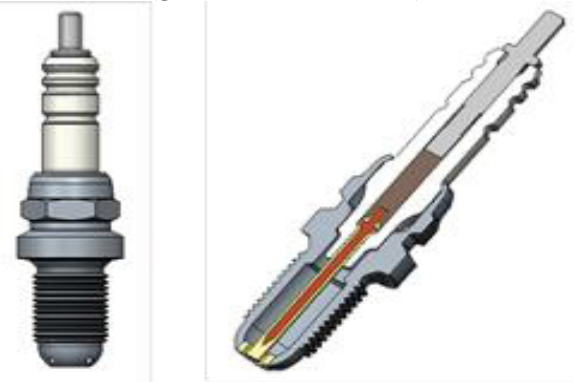

Figure 3. Newly designed volume model for FEM field simulation spark plug with integrated chamber.
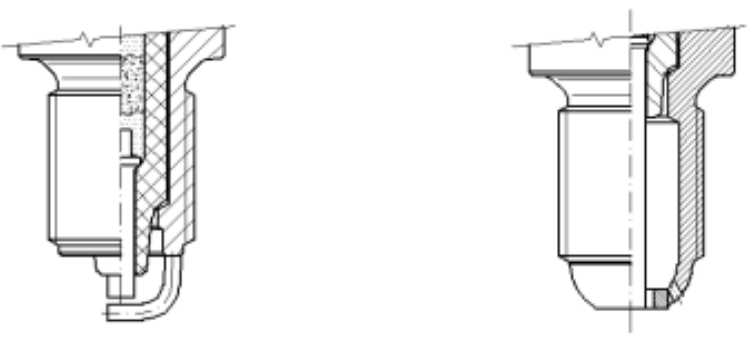

Figure 4. Front view and broken-out section of classic spark plug and spark plug with integrated prepared for manufacture of working samples.

Several construction version changes on spark plugs case M14 (version 1 - version 6) were tested and spark was captured for each version. For type of spark testing the measurement test bench was used (shown on fig. 5). Main parameters of the test bench are: pressure 8bar, voltage $25 \mathrm{kV}$.

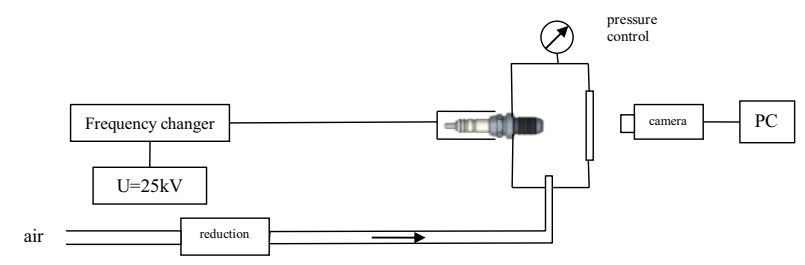

Figure 5. Equipment design.

Table 1. Recording high-voltage discharge at the spark gap for the different endings of lower parts spark plug with integrated chamber. For each variant is a short description of the course and place spark. [10]

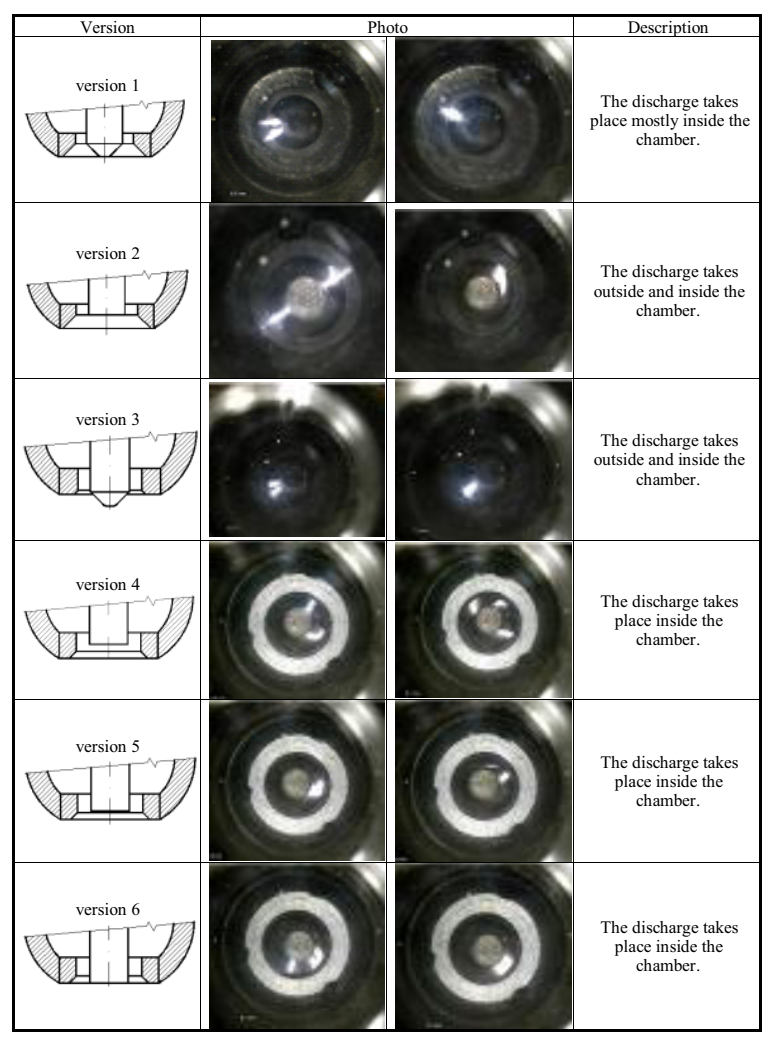


For further experiments with SPWIC on the test engine it was decided to prepare variants in the spark gap variation 2 (with an internal chamber volume of $1 \mathrm{~cm}^{3}$ ) see Table 1. Brisk Company for these SPWIC prepared an insulator with an extended medium electrode. The bottom of the SPWIC case was 3 (hereinafter referred to as SPWIC - 3 holes more recessed $=$ version 2 ) and variant 6 (hereafter referred to as SPWIC - 6 holes more recessed $=$ version 3 ) with "fluted" channels with a diameter of $1.6 \mathrm{~mm}$. These variants were also compared to SPWIC with an internal chamber volume of $0.95 \mathrm{~cm} 3$ denoted as SPWIC -3 holes less recessed $=$ version 1 .

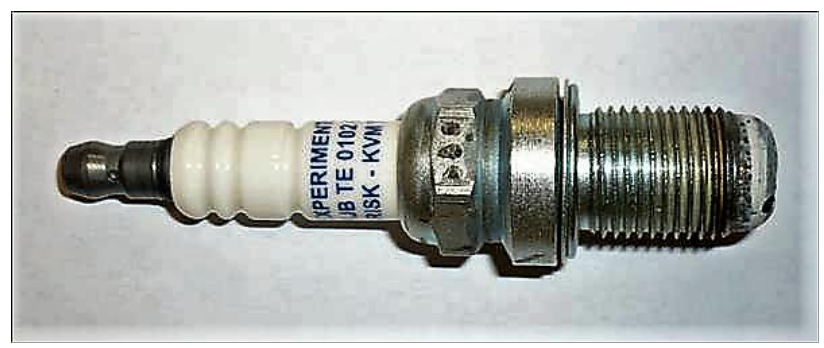

Figure 6. SPWIC design with internal chamber volume $1 \mathrm{~cm}^{3}$

\section{Experiment}

Experimental works on the tested variants of spark plug with integrated chamber were made on testing engine in laboratory belongs to Laboratory of power units. Each variant was prepared as assembly of "prefabricated" spark plugs which basic parts (case and insulator with center electrode) in cooperation with company Brisk Tábor. For measurement was prepared engine EA111.03E (high pressure indication for each cylinder, pressure sensors GU21D and measurement device AVL 619 Indimeter) - parameters are in the Table 2.

Table 2. Engine parameters.

\begin{tabular}{|c|c|}
\hline Type & $\begin{array}{c}\text { SI, 12 valves, } \\
\text { DOHC }\end{array}$ \\
\hline Bore X Stroke & $76,5 \times 86,9 \mathrm{~mm}$ \\
\hline $\begin{array}{c}\text { Number of } \\
\text { cylinders }\end{array}$ & 3 \\
\hline $\begin{array}{c}\text { Swept volume of } \\
\text { engine }\end{array}$ & $1198 \mathrm{~cm}^{3}$ \\
\hline Maximum power & $51 \mathrm{~kW}$ \\
\hline Maximum torque & $112 \mathrm{Nm}$ \\
\hline Compression ratio & $10,5 \pm 0,3: 1$ \\
\hline Cooling & water \\
\hline
\end{tabular}

Based on experience from previous measurements (and especially with regard to the time-consuming performance of the results), the measurement range on the engine was reduced somewhat (in the load characteristics for 3 load levels: low, medium and high). The EA111.03E was equipped with a standard ECU. With SPWIC measurements in speed modes, occasional abnormalities (frequent ECU interventions to set ignition advance - apparently the result of self ignition) were shown in the on-line tracking of the pressures in the engine cylinders, so the measuring range was limited to $3700 \mathrm{rpm}$.

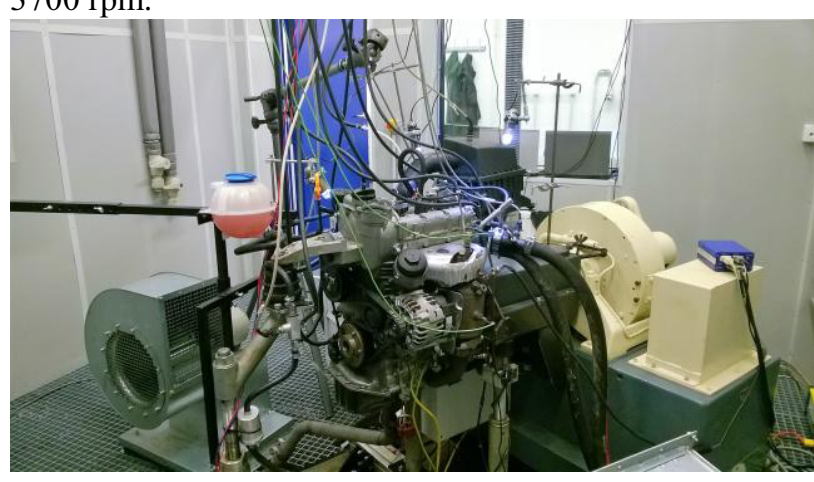

Figure 7. View of engine brake WT150 with engine installed EA111.03E.

\section{Results and discussion}

Selected results from the graphical processing of the measurements made are shown in Figures 8 to 14. From the parameters of the working cycle, only the variability of the values of the mean indicated pressures and the maximum pressures in the engine cylinder were monitored. Their relative comparison for the different spark plugs is shown in Figure 8. At medium speeds and low to medium loads, the $\mathrm{VAR}_{\mathrm{pi}}$ classical spark plug Brisk $\mathrm{A}$ has the lowest variance, the average load has the lowest variance $\mathrm{VAR}_{\mathrm{pi}}$ SPWIC - 3 holes less recessed).

Part of the evaluation of the results from the experimental research was oriented to the dynamics of the process of the combustion process: comparison of the SPWIC with the classic spark plugs shows the graphs in Figures 9, 10 and 11 .

Examples of the aggregate result from the statistical processing of the thermodynamic analysis of the measured pressure curves from the high pressure indication in all engine cylinders with the determination of the crankshaft position at burnout of $5 \%, 10 \%, 50 \%$ and $90 \%$ of the fuel mixture in the cylinder during engine operation with the individual spark plugs are shown in graphs in Figures 12, 13, and 14. The color columns show the mean values of the monitored parameter and the columns on the columns indicate the value range (minimum and maximum) of the monitored parameter in the set of 100 engine operating cycles.

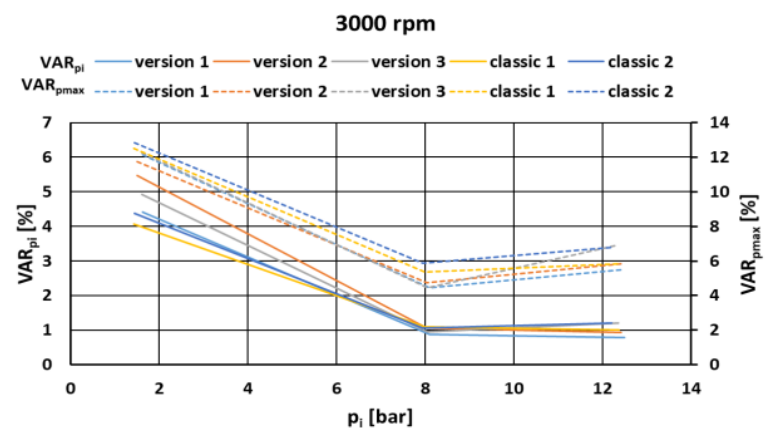

Figure 8. $\mathrm{VAR}_{\mathrm{pi}}$ and $\mathrm{VAR}_{\mathrm{pmax}}$ depending on load for individual SPWIC variants and classic spark plugs. 

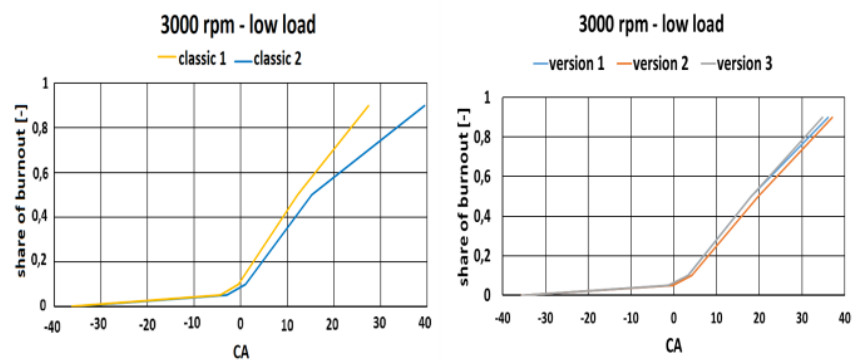

Figure 9. In the low load mode, a petrol engine ignition delay is relatively large (for the illustrated case about $30^{\circ} \mathrm{CA}$ ) as for conventional spark plug and SPWIC. Significant influence is apparently on increased fuel gas in the fresh fuel mixture, and in the SPWIC reduced content of fresh fuel-air mixture in the chamber.
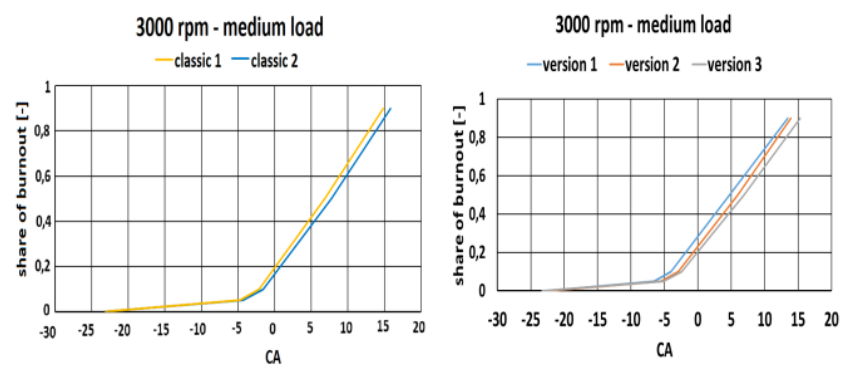

Figure 10. In medium engine load modes, SPWIC has a slightly shorter spillage than a conventional spark plug and a small increase in fuel-burning dynamics in the cylinder.
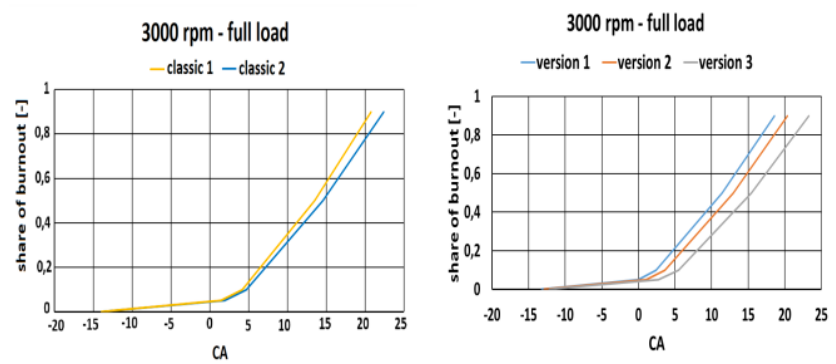

Figure 11. In high load modes, the mutual comparison of SPWIC and classical spark plugs can be described similarly to the average engine load modes shown in Figure 10. Slightly different charging conditions in the engine cylinder during spark ignition with spark plug and SPWIC indicate the likely effect of design variations in the design of individual types of spark plugs.

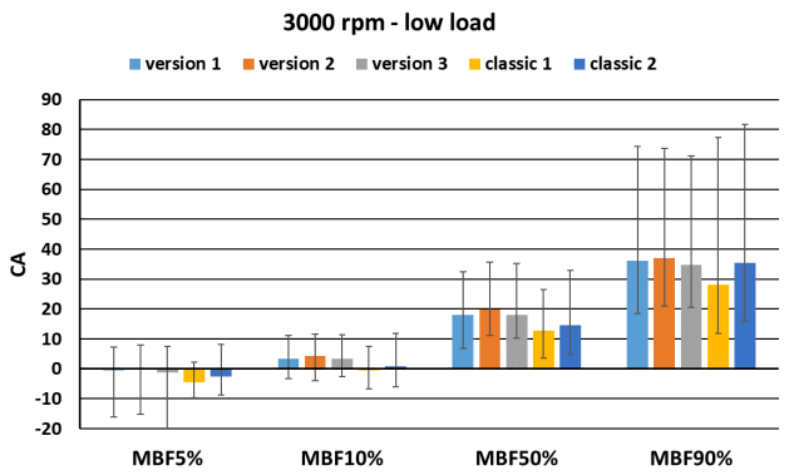

Figure 12. Characteristic points during the cylinder's fuel burning process in very low load modes when ignition of the fuel-air mixture by different spark plugs. Higher fuel-burning dynamics have BRISK spark plugs, with the SPWIC approaching a three-hole and more recessed medium electrode. However, the measurement may be affected by the operational adjustment (in advance and fuel mixture richness), which is set by the ECU according to the instantaneous operating situation and the operation and the ECU algorithm can not be interfered with.

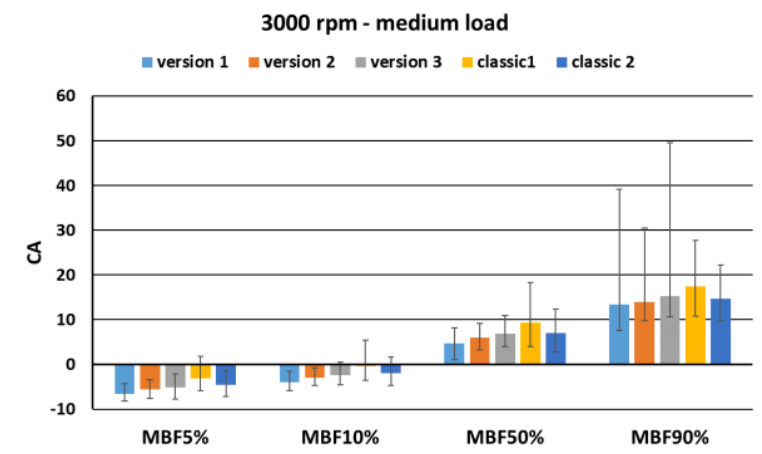

Figure 13. Characteristic points of the fuel-air mixture burning in the cylinder in average engine load modes when ignited by different spark plugs. From the point of view of the dynamics of the combustion process (according to the position of the characteristic points on the crankshaft position) all SPWIC variants are almost comparable to the classic BRISK spark plug A. The unexplained problem for SPWIC is the greater variability in the overall length of the main combustion phase (Q90\%) against the classic spark plugs

3000 rpm - full load

| version 1 | version 2 | version 3 || classic 1 || classic 2

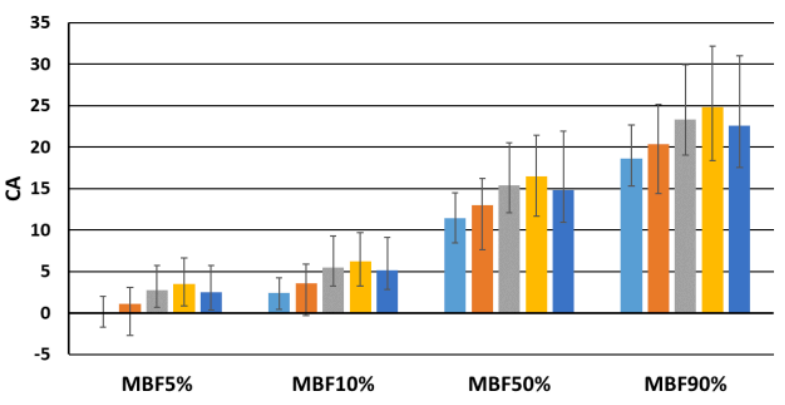

Figure 14. Characteristic points of the burning behavior of the fuel mixture in the cylinder in high engine load conditions when ignited by different spark plugs. The most advantageous course of combustion fuel burning in a cylinder has a SPWIC with 3 holes and a lower middle electrode in the center hole of the bottom of the chamber (spark plug housing).

\section{Conclusion}

The results show the positive effect of SPWIC over SP. From medium to full load, the variability parameters of both the mean pressure and the maximum pressure are reduced. Obviously, it is also faster burnout share of the cylinder charge when using SPWIC medium to full load.

\section{Acknowledgements}

The results of this project LO1201 were obtained through the financial support of the Ministry of Education, Youth and Sports in the framework of the targeted support of the "National Programme for Sustainability I" and the OPR\&DI project Centre for Nanomaterials, Advanced Technologies and Innovation CZ.1.05/2.1.00/01.0005. 


\section{References}

1. HEYWOOD, John B. Internal combustion engine fundamentals. New York: McGraw-Hill, c1988. ISBN 00-702-8637-X.

2. ATTARD, William P., Elisa TOULSON, Andrew HUISJEN, Xuefei CHEN, Guoming ZHU a Harold SCHOCK. Spark Ignition and Pre-Chamber Turbulent Jet Ignition Combustion Visualization. In: . s. -. DOI: 10.4271/2012-01-0823.

3. ATTARD, William. Turbulent Jet Ignition Prechamber Combustion System for Spark Ignition Engines [online]. Inventor: William Attard. 01. 11. 2011. US20120103302 A1. In: http://www.google.com/patents/US20120103302

4. Engine Technology International. 2017, 2017(January). ISSN 1460-9509.

5. DE CASTRO RADICCHI, Fábio, Raphael Meireles BRAGA, Raniro DE OLIVEIRA ALVARENGA COELHO, Roberto Berlini Rodrigues DA COSTA a Ramón Molina VALLE. Numerical Analysis of the
Fluid Flow in a Prechamber for a Spark-ignition Engine. In: . s. -. DOI: 10.4271/2015-36-0289.

6. MWM GmbH. Spark Plug [online]. Inventors: Olaf Berger, Friedrich Schäfer. 25. 07. 2012. EP 2690 726 A1. In: http://www.freepatentsonline.com/EP2690726.pdf

7. BLAŽEK, Josef. Výzkum a vývoj komůrkového zážehu pro vozidlový motor. Liberec, 2008. Disertační práce. Technická univerzita $\mathrm{v}$ Liberci. Vedoucí práce doc. Ing. Lubomír Moc, CSc.

8. BEROUN, Stanislav. Termodynamika pracovniho oběhu PSM, spalovací proces v PSM. Technická univerzita v Liberci, 2009.

9. BEROUN, Stanislav. Základy teorie hoření, mechanizmus spalovacího procesu $v$ pistových spalovacich motorech. Technická univerzita v Liberci, 1998.

10. DITTRICH, Aleš, Stanislav BEROUN, Pavel BRABEC a Lukáš MIKULANIN. Spark plug with integrated chamber. 5th International Conference on Mechanics, Simulation and Control. 